\title{
Reduced association of anti-apoptotic protein Mcl- I with E3 ligase Mule increases the stability of Mcl-I in breast cancer cells
}

\author{
S Pervin*, 1,2, A Tran', L Tran², R Urman², M Braga', G Chaudhuri, ${ }^{2,3}$ and R Singh ${ }^{1,2,3}$ \\ 'Department of Internal Medicine, Charles Drew University of Medicine and Science, 3084 Hawkins Building, 1731 East 120 th Street, \\ Los Angeles, CA 90059, USA; '2Department of Obstetrics and Gynecology, David Geffen School of Medicine at UCLA, 22-1 I5 CHS, 10833 Le Conte \\ Avenue, Los Angeles, CA 90095-7358, USA; '3onsson Comprehensive Cancer Center, David Geffen School of Medicine at UCLA, I0833 Le Conte \\ Avenue, Los Angeles, CA 90095-7358, USA
}

BACKGROUND: Mechanisms that increase resistance to apoptosis help promote cellular transformation. Cancer cells have deregulated apoptotic pathways, where increased expression and stability of anti-apoptotic proteins $\mathrm{Mcl}-\mathrm{I}$ and $\mathrm{Bcl}-2$ increases resistance to apoptosis. Pathways that increase the stability of proteins in cancer cells remain poorly understood.

METHODS: Using human mammary epithelial and established breast cancer cell lines, we assessed the mechanisms that increase the stability of anti-apoptotic proteins in breast cancer cells by caspase assay, western blot, small-inhibitory RNA treatment and immunoprecipitation.

RESULTS: While breast cancer cells were resistant to de novo inhibition of protein synthesis, a rapid proteosome-mediated degradation of $\mathrm{Mcl}-\mathrm{I}$ and $\mathrm{Bcl}-2$ induced apoptosis in mammary epithelial cells. Although Mule, an E3 ligase that targets Mcl-I for degradation was expressed in mammary epithelial and breast cancer cell lines, rapid increase of polyubiquitinated $\mathrm{Mcl}-\mathrm{I}$ and Bcl-2 was detected only in mammary epithelial cells. Only transient formation of the Mule-Mcl-I complex was detected in breast cancer cells. Downregulation of pERKI/2 in breast cancer cells reduced Mcl-I levels and increased Mcl-I/Mule complex.

CONCLUSION: Our findings suggest that reduced Mule/Mcl-I complex has a significant role in increasing the stability of Mcl-I in breast cancer cells and increased resistance to apoptosis.

British Journal of Cancer (20II) I 05, 428-437. doi:I0.1038/bjc.201।.242 www.bjcancer.com

Published online 5 July 2011

(c) 201 I Cancer Research UK

Keywords: apoptosis; ubiquitin; proteosome; E3 ligase

Progression of tumourigenesis is dependent upon many factors including mechanisms that increase resistance to apoptosis. Cancer cells have developed effective mechanisms to resist various stress-induced apoptosis (McCubrey et al, 2007; Djeu and Wei, 2009). Evasion of apoptosis by cancer cells differ from normal cell, which are relatively more sensitive to mitochondria-mediated apoptosis (Müllauer et al, 2000; Wang et al, 2003; Jetzt et al, 2009). Bcl-2 family of proteins have a key role in regulating apoptosis, where the ratio of anti-apoptotic (Bcl-2, Bcl-XL and Mcl-1) and pro-apoptotic (Bax, Bad and PUMA) members maintain integrity of the mitochondrial membrane (Kutuk and Letai, 2008). Common cancers such as breast and prostate express high levels of Bcl-XL and Bcl-2 proteins, which inhibit mitochondria-mediated apoptosis (Nuñez et al, 1991; Callagy et al, 2008). In addition to increased transcription, additional mechanisms that increase stability of anti-apoptotic proteins in cancer cells remain poorly understood (Abdelmohsen et al, 2007; Shimazu et al, 2007). Some of the known mechanisms by which proteins are stabilised in breast cancer cells are through acetylation, glycosylation or increased association with various chaperones. In MCF-7 cell line, Raf-1 exists in a complex with heat shock protein hsp-90 and this complex is essential for Raf-1 protein stability (Schulte et al, 1995). Another

*Correspondence: Dr S Pervin; E-mail: shehlapervin@cdrewu.edu Revised 9 May 201 I; accepted 3 June 20 I I; published online 5 July 201 I protein that gets stabilised in breast cancer is AP- $2 \alpha$, a transcription factor that binds to HER-2/neu gene promoter and has a half-life of $30 \mathrm{~h}$ compared with $1 \mathrm{~h}$ in normal cells (Li et al, 2006). This increased stability of AP- $2 \alpha$ protein has been found to induce HER-2 overexpression, which has an adverse prognosis in $10-34 \%$ of breast cancers (Pellikainen and Kosma, 2007).

The ubiquitin-proteosome machinery, a common pathway for protein degradation, has been implicated in regulating protein stability, cell viability and apoptosis (McBride et al, 2003; Thompson et al, 2008). Proteins targeted for proteosomal degradation get polyubiquitinated at specific lysine residues through a multistep process mediated by E1, E2 and E3 ligases. The ubiquitination mechanism consists of three steps: (1) activation of ubiquitin ( $\mathrm{ub}$ ) monomers by E1 ligase, (2) transfer of activated ub from E1 ligase to E2 ligase and (3) transfer of the ub polymers from E2 ligase to the protein targeted for degradation by E3 ligase. An ubiquitin chain forming a specific lysine-lysine linkage serves as a signal for degradation of proteins (Sun, 2006; Petroski, 2008). Poorly understood aberrations in the ubiquitinproteosome machinery could increase stability of anti-apoptotic proteins in breast cancer cells. We used cycloheximide (CHX) to inhibit de novo protein synthesis and investigated mechanisms that increase the stability of anti-apoptotic proteins in breast cancer cells. We find that $\mathrm{CHX}$ treatment promotes mitochondriamediated apoptosis through decline in levels of Mcl-1 and Bcl-2 in normal mammary epithelial cells. In breast cancer cells, reduced ubiquitination and degradation of Mcl-1 and Bcl-2 was detected 
with CHX treatment. We demonstrate that unstable binding of Mcl-1 with E3 ligase Mule could be one of the prominent mechanisms that increases stability of Mcl-1 in breast cancer cells.

\section{MATERIALS AND METHODS}

\section{Cell culture}

Human breast cancer cell lines MDA-MB-231, MDA-MB-468 and MCF-7 were obtained from American Type Culture Collection (Manassas, VA, USA). These cells were cultured in DMEM containing $10 \mathrm{~mm}$ non-essential amino acids, $2 \mathrm{~mm}$ L-glutamine, $10 \mathrm{~g} \mathrm{ml}^{-1}$ insulin and $10 \%$ fetal bovine serum. MCF-10A, a spontaneously immortalised untransformed human mammary epithelial cell line was obtained from Robert J Pauley (Barbara Ann Karmanos Cancer Institute, Detroit, MI, USA). HMLE, a human mammary epithelial cell line immortalised by the introduction of SV40 large-T oncogene and hTERT was obtained from Professor Robert Weinberg (Whitehead Institute at MIT, Cambridge, MA, USA). MCF-10A and HMLE were cultured in DMEM: Ham's F-12 (1:1) supplemented with 5\% equine serum, $10 \mathrm{~mm}$ HEPES, $10 \mu \mathrm{g} \mathrm{ml}^{-1}$ insulin, $20 \mathrm{ng} \mathrm{ml}^{-1}$ epidermal growth factor, $100 \mathrm{ng} \mathrm{ml}^{-1}$ cholera enterotoxin and $0.5 \mu \mathrm{g} \mathrm{ml}^{-1}$ hydrocortisone (Pervin et al, 2003).

\section{Chemicals}

Antibodies used were from the following suppliers: rabbit polyclonal anti-Ub (G0805), anti-Mcl-1 from Santa Cruz Biotech Inc. (Santa Cruz, CA, USA); rabbit polyclonal anti-Mule (A300486A; Bethyl Laboratories, Montgomery, TX, USA), mouse antiHRF from BD Biosciences Pharmingen (San Diego, CA, USA); rabbit anti-Puma from Abcam (Boston, MA, USA); rabbit polyclonal anti-caspase-3 (65906E), mouse monoclonal anticytochrome $c(65981 \mathrm{~A})$ and rabbit polyclonal ERK1/2 MAP kinase (9102) from New England Biolabs (Ipswich, MA, USA); mouse monoclonal anti-Bcl-2 (Ab-1) from Calbiochem (La Jolla, CA, USA). Cycloheximide and MG132 were obtained from Sigma (St Louis, MO, USA).

\section{TUNEL assay}

The TUNEL assay was performed using ApoAlert DNA Fragmentation Assay Kit from Clontech (Palo Alto, CA, USA). Cells $\left(3 \times 10^{6}\right)$ were collected by centrifugation and washed twice with PBS. Cells were fixed in $1 \%$ formaldehyde-PBS at $4{ }^{\circ} \mathrm{C}$ for $20 \mathrm{~min}$ and incubated with nucleotide mixture and terminal deoxynucleotidyl transferase enzyme for analysis in a Becton Dickinson Flow Cytometer (Singh et al, 2000).

\section{Caspase assay}

Cells were lysed in insect cell lysis buffer containing $50 \mathrm{~mm}$ HEPES, $100 \mathrm{~mm} \mathrm{NaCl}, 2 \mathrm{~mm}$ EDTA, 0.1\% 3-((3-cholamidopropyl) dimethylammonio)-1-propanesulfonic acid (CHAPS), $10 \%$ sucrose, $5 \mathrm{~mm}$ DTT and $1 \times$ protease inhibitor for $30 \mathrm{~min}$ at $4{ }^{\circ} \mathrm{C}$. The lysates were used for caspase-3 $(30 \mu \mathrm{g})$ and caspase-9 $(50 \mu \mathrm{g})$ enzymatic assays using respective substrates. The cleaved fluorescent substrate was quantified using a Versa Fluro flurometer (Bio-Rad, Hercules, CA, USA), with excitation at $380 \mathrm{~nm}$ and emission at $440 \mathrm{~nm}$ (Pervin et al, 2007).

\section{Cell fractionation and cytochrome $c$ detection}

Cytochrome $c$ release into the cytosol was detected as described previously with minor modifications (Pervin et al, 2003; Pervin et al, 2007). Briefly, $6 \times 10^{6}$ cells were harvested and washed with PBS. The cells were suspended in buffer A $(20 \mathrm{~mm}$ HEPES-KOH (pH 7.5), $10 \mathrm{~mm} \mathrm{KCl,} 1.5$ mm $\mathrm{MgCl}_{2}$, 1 mм EDTA, 1 mm EGTA, $1 \mathrm{~mm}$ DTT, $250 \mathrm{~mm}$ sucrose and $1 \times$ protease inhibitor cocktail) and were homogenised by Dounce homogeniser; unbroken cells and nuclei were removed by centrifugation at $1000 \mathrm{~g}$ for $20 \mathrm{~min}$. The cytosolic fraction was analysed by western blot with an anticytochrome c monoclonal antibody (7H8 2C12) or with an antiGAPDH antibody (Pervin et al, 2003, 2007).

\section{Western analysis}

Cells were lysed in cell lysis buffer (50 mM HEPES, pH 7.5; $1 \mathrm{~mm}$ DTT, $150 \mathrm{~mm} \mathrm{NaCl}, 1 \mathrm{~mm}$ EDTA, $0.1 \%$ Tween $20,10 \%$ glycerol, $10 \mathrm{mM} \alpha$-glycerophosphate, $1 \mathrm{mM} \mathrm{NaF}, 0.1 \mathrm{~mm}$ orthovanadate, $10 \mu \mathrm{g} \mathrm{ml}^{-1}$ leupeptin, $10 \mu \mathrm{g} \mathrm{ml}^{-1}$ aprotinin and $0.1 \mathrm{mM} \mathrm{PMSF}$ ) and incubated at $4{ }^{\circ} \mathrm{C}$ for $30 \mathrm{~min}$ for analysis of cytosolic proteins. Lysates $(100 \mu \mathrm{g})$ were resolved electrophoretically on $4-15 \%$ gradient SDS-polyacrylamide gel and electro transferred to a polyvinylidine difluoride membrane (Bio-Rad) using a tank blot procedure (Bio-Rad Mini Protean II). The membranes were incubated with various primary antibodies ( $1: 1000$ dilution) and respective horseradish peroxidase-linked secondary antibody ( $1: 1000$ dilution) (Amersham Corp., Piscataway, NJ, USA) for $1 \mathrm{~h}$. Immunoreactive bands were visualised by ECL detection system (Amersham) (Singh et al, 2000; Pervin et al, 2003, 2007).

\section{Immunoprecipitation}

Cells were lysed in lysis buffer containing $50 \mathrm{~mm}$ Tris/HCl, $\mathrm{pH} 8.0$, $300 \mathrm{~mm} \mathrm{NaCl}, 10 \mathrm{~mm} \mathrm{MgCl}$, 0.5\% Igepal Ca-630 (Sigma), $1 \mathrm{~mm}$ EDTA and anti-protease cocktail (Roche, San Francisco, CA, USA). Supernatant $(500 \mu \mathrm{g})$ were pre-cleared by incubation $\left(4 \mathrm{~h}\right.$ at $\left.4^{\circ} \mathrm{C}\right)$ once with Protein A/G-agarose (Santa Cruz Biotechnology) and once with Protein A/G-agarose pre-incubated with pre-immune serum. The pre-cleared lysate was adjusted to $150 \mathrm{~mm} \mathrm{NaCl}$ and $0.25 \%$ Igepal Ca-630 and subjected to overnight immunoprecipitation with the respective antibodies. The mixtures were incubated further for $4 \mathrm{~h}$ at $4{ }^{\circ} \mathrm{C}$ with $50 \mu \mathrm{l}$ of Protein A/G-agarose and processed for western blot analysis (Pervin et al, 2007).

\section{Small-interfering (siRNA) transfection}

Breast cancer cells were propagated into six-well plates at $2 \times 10^{5}$ cells per well, grown for $24 \mathrm{~h}$ in complete medium followed by transfection with ON-TARGET plus Smart pool siRNA specific to Puma, HRF and Mcl-1 (Dharmacon, Chicago, IL, USA) or scrambled siRNA-negative control at a final concentration of $20 \mathrm{nM}$ using lipofectamine reagent. Mule siRNA sequence ( $5^{\prime}$-AAU UGCUAUGUCUCUGGGACA- $3^{\prime}$ ) used to target human Mule was designed as described before (Chen et al, 2005; Parsons et al, 2009). Efficiency of transfection was monitored by analysing the cell lysates after 3 days of transfection by western blot analysis using respective antibodies (Pervin et al, 2007). siRNA transected cells were further subjected to vehicle or CHX treatment for various time points, lysed and analysed by western blot analysis or enzymatic assay for caspase- 3 .

\section{Statistical analysis}

Data are presented as mean \pm s.e.m. Student's $t$-test was performed for comparison between two groups. For statistical analysis of more than two groups, data were analysed by ANOVA, and pairwise comparisons were performed by Tukey's posttest procedure. $P$-values $<0.05$ were considered statistically significant. 


\section{RESULTS}

\section{Resistance of breast cancer cells to $\mathrm{CHX}$-induced apoptosis}

We initially performed $S^{35}$ methionine uptake assays to determine the concentrations and duration of $\mathrm{CHX}$ treatment required to inhibit protein synthesis in both mammary epithelial and breast cancer cells. Significant inhibition of protein synthesis was observed within $6 \mathrm{~h}$ of $\mathrm{CHX}$ treatment in the normal mammary epithelial cells $\left(100 \mu \mathrm{g} \mathrm{ml}^{-1} \mathrm{CHX}\right)$ and breast cancer cells $\left(200 \mu \mathrm{g} \mathrm{ml}^{-1} \mathrm{CHX}\right)$ (Figure 1A). Only in mammary epithelial cells, CHX treatment induced DNA fragmentation and cell death as detected by TUNEL assay and trypan blue exclusion method, respectively (Figure 1B). We next examined caspase-3, an executioner caspase in the apoptotic cascade that commits cells to apoptosis by inducing DNA fragmentation along with other prominent changes. Caspase-3 activity, measured using DEVDAMC as a substrate, significantly increased in CHX-treated (6-16h) MCF-10A and HMLE cells, while no activity was detected in breast cancer cells (Figure 1C). We also examined the activation of caspase-9, which functions upstream of caspase-3, by using Ac-LEHD-AMC as substrate. Caspase- 9 activities followed the similar pattern as caspase- 3 and increased 5-6 folds at $16 \mathrm{~h}$ only in CHX-treated MCF-10A and HMLE cells, while no significant increased activity was detected in breast cancer cells (Figure 1D). Breast cancer cell lines became cytostatic with CHX treatment at $24 \mathrm{~h}$ and no significant increase in caspase-3/9 activities or apoptosis was detected at $16 \mathrm{~h}$ (Figures $1 \mathrm{~B}-\mathrm{D}$ ) or even $24-48 \mathrm{~h}$ (data not shown). Cytostatic cells were viable even until $72 \mathrm{~h}$ of CHX treatment as assessed by trypan blue exclusion assay and no TUNEL-positive cells were detected in that time frame (data not shown).

To determine whether CHX-induced increase in caspase- 3 and caspase- 9 activities were mitochondria dependent in normal mammary epithelial cells, the cells were fractionated and the cytosolic fractions were analysed for an increase in cytochrome $c$ levels by western blot analysis. We found increased cytochrome $c$ levels at $16 \mathrm{~h}$ in the cytoplasm of CHX-treated MCF-10A and HMLE cells, confirming the involvement of mitochondriamediated apoptotic pathway (Figure 1E). No increase in cytosolic cytochrome $c$ was found in breast cancer cells even at $48 \mathrm{~h}$ of $\mathrm{CHX}$ treatment (data not shown). Our data therefore indicate that de novo inhibition of protein synthesis induces mitochondriamediated apoptosis only in normal mammary epithelial cells, while breast cancer cells were resistant to this treatment.

\section{Reduced ubiquitination and increased stability of anti-apoptotic proteins in cancer cells}

Since CHX treatment increased cytosolic cytochrome $c$ in MCF$10 \mathrm{~A}$ and HMLE cells, we examined the stability of Mcl-1 and Bcl-2 proteins that maintain the integrity of mitochondrial membrane. The stability of anti-apoptotic proteins $\mathrm{Mcl}-1$ and $\mathrm{Bcl}-2$ was also assessed in these MDA-MB-468, MDA-MB-231 and MCF-7 breast cancer cells after treatment with CHX $\left(200 \mu \mathrm{g} \mathrm{ml}^{-1}\right)$. Mcl-1 levels were reduced in CHX-treated MCF-10A $(52 \pm 6 \%)$ and HMLE $(62 \pm 6 \%)$ cells at $3 \mathrm{~h}$ (Figure $2 \mathrm{~A}$, left panel); whereas, Bcl-2 levels were reduced by $66 \pm 7 \%$ in MCF-10A and $48 \pm 6 \%$ in HMLE cells after similar treatments at $16 \mathrm{~h}$ as assessed by western blot analysis (Figure 2A, right panel). No significant decline in the levels of Mcl1 and Bcl-2 was observed in the cancer cell lines where the overall levels remained relatively stable and even increased at $16-24 \mathrm{~h}$ of CHX treatment (Figure 2A, left and right panels). The decline in Mcl-1 and Bcl-2 in CHX-treated normal cells was further confirmed by immunoprecipitation assays. Mcl-1 and Bcl-2 were immunoprecipitated with $\mathrm{Mcl}-1$ or $\mathrm{Bcl}-2$ antibodies from $\mathrm{CHX}-$ treated lysates, which were further immunoblotted with their respective antibodies. Immunoprecipitation analysis confirmed that the decline in Mcl-1 (Figure 2B, left panel) and Bcl-2 (data not shown) was only in CHX-treated normal mammary epithelial cells but not in the CHX-treated breast cancer cells (Figure 2B, right panel).

We next examined the mechanism(s) that promote selective decline of Mcl-1 and Bcl-2 only in MCF-10A and HMLE cells. To determine whether the ubiquitination of Mcl-1 and Bcl-2 increased with CHX treatment, the cell lysates at various time points were immunoprecipitated with ubiquitin antibody and immunoblotted for Mcl-1. We found increased levels of ubiquitinated Mcl-1 in CHX-treated MCF-10A at $16-24 \mathrm{~h}$ (Figure 2C, left panel), while in MDA-MB-468 cells, no prominent ubiquitination of Mcl-1 was detected (Figure 2C, right panel). Similar results were obtained when total cellular ubiquitinated proteins were immunoprecipitated and immunoblotted with Bcl-2. Ubiquitinated Bcl-2 was found only in CHX-treated MCF-10A cells but not in MDA-MB-231 cells (data not shown).

To further determine whether ubiquitinated Mcl-1 and Bcl-2 in normal mammary epithelial cells were degraded through the $26 \mathrm{~S}$ proteosomal complex, a chemical inhibitor of the proteosomal machinery, MG132 was used. The stability of Bcl-2 and Mcl-1 proteins was examined by western blotting in cells pre-incubated with MG132 for $2 \mathrm{~h}$ followed by CHX treatment. Treatment with MG132 inhibitor completely attenuated the decline of Mcl-1 in CHX-treated human mammary epithelial cells, confirming the involvement of the $26 \mathrm{~S}$ proteasomal degradation pathway (Figure 3A). However, CHX-induced decline of Bcl-2 levels was only partially attenuated with MG132 treatment in the normal mammary epithelial cells (Figure 3A). Our data, therefore, may suggest that MG132 selectively inhibits CHX-induced degradation of Mcl-1 but Bcl-2 degradation in response to $\mathrm{CHX}$ may not be entirely dependent on proteasomal pathways in mammary epithelial cells. Pre-treatment with the inhibitor MG132 followed by $\mathrm{CHX}$ exposure resulted in no significant change in the Mcl-1 or Bcl-2 levels in the breast cancer cell lines MDA-MB-231 (Figure 3A), MDA-MB-468 and MCF-7 (data not shown). Pretreatment with the inhibitor, MG132, also attenuated the CHXinduced dramatic increase in caspase- 3 activity in MCF-10A cells (Figure 3B, left panel). On the other hand, in breast cancer cells, no significant change in caspase-3 activity was observed with or without MG132 pre-treatment followed by CHX exposure (Figure 3B, right panel). Furthermore, we detected higher levels of polyubiquitinated proteins that accumulate without degradation in MG132-treated MCF-10A but not in MDA-MB-468 cells (Figure 3C). Therefore, our results indicate that inhibition of protein synthesis in MCF-10A and HMLE cells increases rapid degradation of $\mathrm{Mcl}-1$ and to some extent $\mathrm{Bcl}-2$ by ubiquitinproteosome machinery.

\section{Reduced association of Mcl-1 with Mule in breast cancer cells}

We next examined the key players or mechanisms that increased the ubiquitination and degradation of $\mathrm{Mcl}-1$ and $\mathrm{Bcl}-2$ in mammary epithelial cells as well as their aberrations in breast cancer cells. E3 ligase, which targets proteins for degradation, has been characterised for Mcl-1 but not for Bcl-2. We examined the expression of Mule, the specific E3 ligase for Mcl-1 by western blot analysis in both the normal mammary epithelial and breast cancer cells. Mule was constitutively expressed in normal mammary epithelial and breast cancer cells (in some breast cancer cell lines Mule was induced by CHX treatment). The protein level of Mule was also comparable between MCF-10A and MDA-MB-468 cells, while it was induced in MDA-MB-231 cells at 6-16h of $\mathrm{CHX}$ treatment (Figure 4A). The mRNA expression of Mule as determined by real-time qPCR in all the cell lines were examined, which followed similar pattern as that of the proteins (data not shown). 

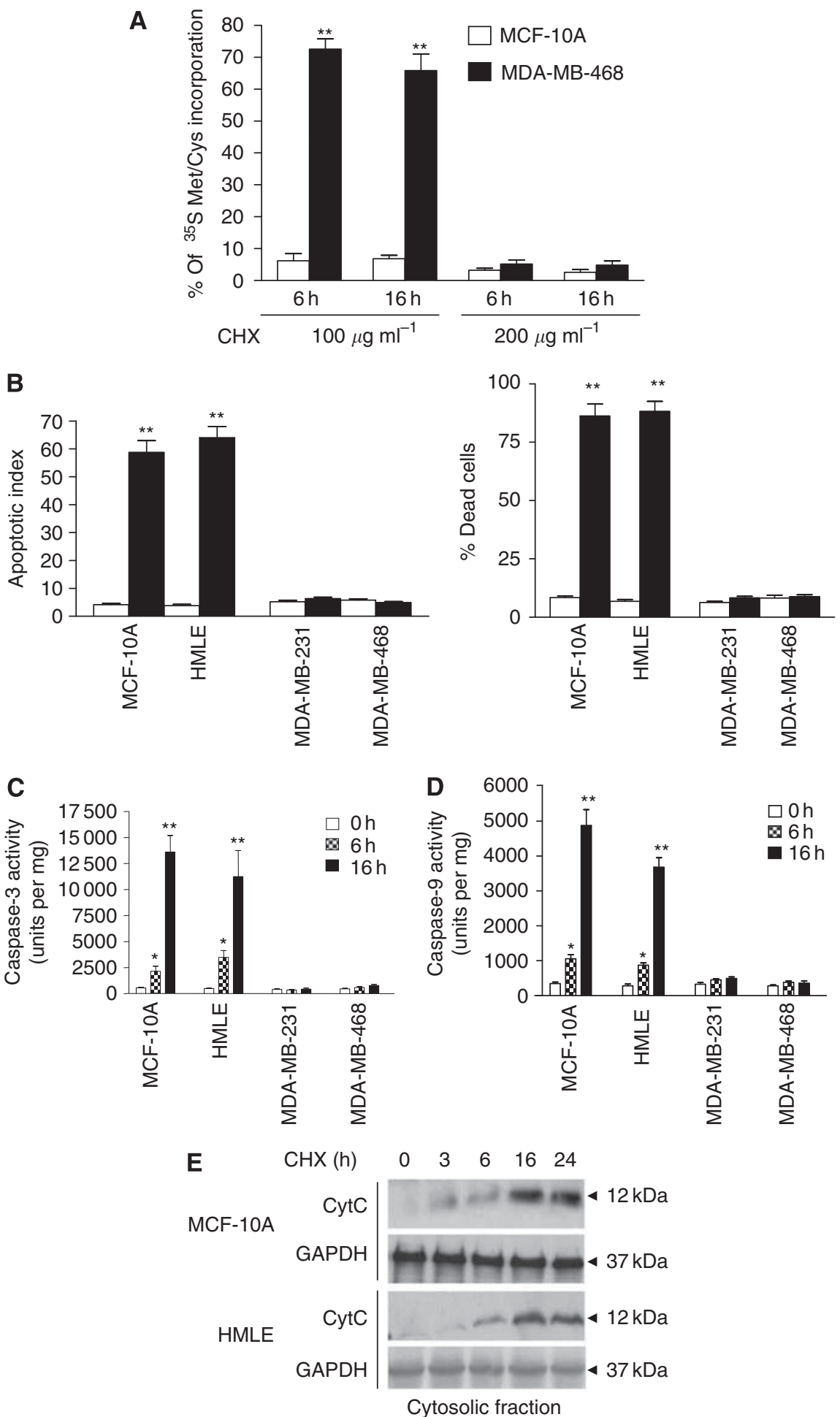

Figure I Resistance of breast cancer cells to cycloheximide (CHX) treatment. (A) MCF-IOA and MDA-MB-468 cells treated with I00-200 $\mu$ g ml ${ }^{-1}$ of $\mathrm{CHX}$ for 6 or $16 \mathrm{~h}$ were harvested following $4 \mathrm{~h}$ of incubation with $\mathrm{S}^{35}$ Met/Cys. The cells were lysed and $\mathrm{S}^{35}$ Met/Cys incorporation into proteins was examined. (B) (Left panel) Cells treated with CHX $\left(200 \mu \mathrm{g} \mathrm{ml}^{-1}\right)$ for $16 \mathrm{~h}$ and DNA fragmentation was assessed by TUNEL assay. (Right panel) Cells treated with CHX $\left(200 \mu \mathrm{g} \mathrm{ml}^{-1}\right)$ for $16 \mathrm{~h}$ and cell viability was assessed by trypan blue assay, white open bar $(0 \mathrm{~h})$; black closed bar (I6 h). (C) Cells treated with $\mathrm{CHX}\left(200 \mu \mathrm{g} \mathrm{ml}^{-1}\right)$ for 6 and $16 \mathrm{~h}$ were lysed and $30 \mu \mathrm{g}$ of the lysate was subjected to fluorometric assay for caspase-3 activity. (D) Cells treated with $\mathrm{CHX}\left(200 \mu \mathrm{g} \mathrm{ml}^{-1}\right)$ for 6 and $16 \mathrm{~h}$ were lysed and $50 \mu \mathrm{g}$ lysates were subjected to fluorometric assay for caspase-9 activity. (E) MCF- IOA and HMLE cells were treated with $\mathrm{CHX}\left(200 \mu \mathrm{g} \mathrm{ml}{ }^{-1}\right)$ for various time points $(0-24 \mathrm{~h})$ and subjected to mitochondria and cytosolic fractionation. Western blot analysis was performed using $100 \mu \mathrm{g}$ of cytosolic fraction using cytochrome $\mathrm{c}$ antibody. Data represent mean \pm s.e.m. of four independent experiments in triplicates (asterisks denote statistically significant values compared with untreated control group, $* P \leqslant 0.05$ and $* * P \leqslant 0.0$ I). 

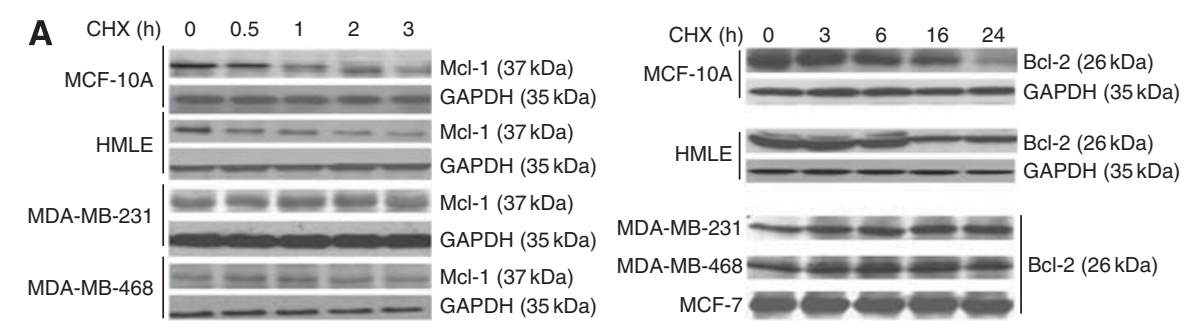

B
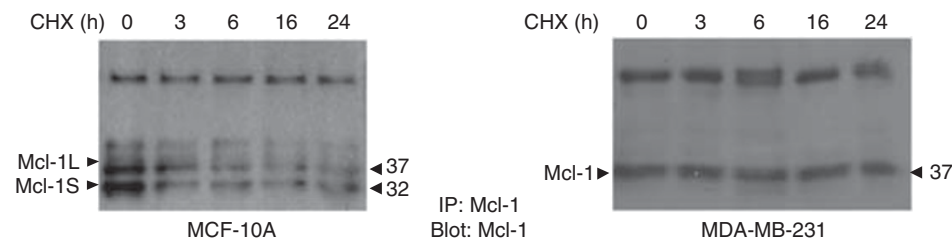

C
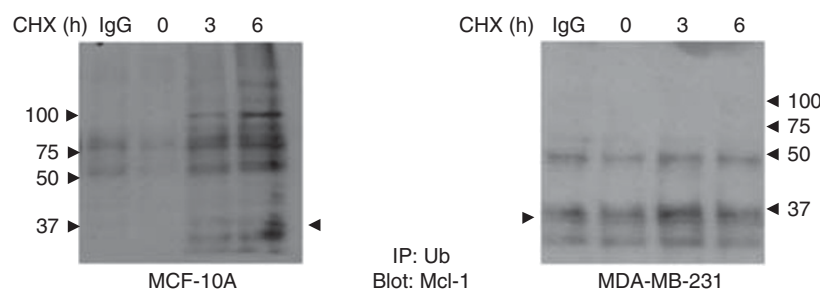

Figure 2 Reduced ubiquitination and increased stability of $\mathrm{Mcl}-\mathrm{I}$ and $\mathrm{Bcl}-2$ in breast cancer cells treated with $\mathrm{CHX}\left(200 \mu \mathrm{g} \mathrm{ml} \mathrm{l}^{-1}\right)$. (A) Cells treated with $\mathrm{CHX}$ for various time points and cell lysates (I00 $\mu \mathrm{g}$ ) were subjected to western blot analysis for Mcl-I and GAPDH (left panel) and Bcl-2 and GAPDH (right panel) proteins. (B) CHX-treated cell lysates $(500 \mu \mathrm{g})$ from MCF-IOA (left panel) and MDA-MB-23I (right panel) were subjected to immunoprecipitation with anti-Mcl-I antibody and immunoblotted for Mcl-I. (C) CHX-treated cell lysates (500 $\mu \mathrm{g}$ ) from MCF-I0A (left panel) and MDAMB-23I (right panel) were subjected to immunoprecipitation with anti-Ub antibody and immunoblotted for Mcl-I.

Since ubiquitination of Mcl-1 was reduced in breast cancer cells even though Mule was constitutively expressed or induced by $\mathrm{CHX}$, we examined the association of Mcl-1 and Mule by immunoprecipitation assays. Mule was immunoprecipitated from CHX-treated cell lysates of MCF-10A and MCF-7 cells and immunoblotted with Mcl-1 antibody. In MCF-10A and HMLE cells, we found increased Mcl-1 and Mule complex between 6-24 h of $\mathrm{CHX}$ treatment (Figure 4B, left panel). We also performed immunoprecipitation of CHX-treated MCF-10A and MCF-7 cells by Mule followed by western blotting with anti-Bcl-2 antibody. We did not find any significant association of Mule with Bcl-2 in MCF$10 \mathrm{~A}$ cells (Figure 4B, bottom panel) or in MCF-7 cells (data not shown). We also confirmed this prolonged association between Mule and Mcl-1 in CHX-treated normal mammary epithelial cells by immunoprecipitating Mcl-1 and blotting for Mule (Figure 4C, left panel). However, in all the breast cancer cell lines examined, we were unable to detect any prolonged association of Mcl-1 and Mule between 0 and $36 \mathrm{~h}$ of CHX treatment. In MDA-MB- 468 cells, we could detect only transient association of Mcl-1 and Mule at $12-16 \mathrm{~h}$, and at each of these time points where the complex was detected, there was a sharp decline in Mule-Mcl-1 complex (Figure 4B, right panel). In MCF-7 cells, we could detect association between Mcl-1 and Mule only at $12 \mathrm{~h}$ (Figure 4C, right panel); while in MDA-MB-231 cells, very weak association was detected at 24 and $48 \mathrm{~h}$ (data not shown). Our results indicate that unstable association between Mule and Mcl-1 may contribute to decreased ubiquitination and degradation of $\mathrm{Mcl}-1$ in breast cancer cells. We were unable to detect significant association of another known E3 ligase $\beta$-TrCP with Mcl-1 in either normal mammary epithelial or breast cancer cells (data not shown).

In order to further investigate the role of Mule during CHXinduced apoptosis in normal mammary epithelial cells, we downregulated Mule expression by siRNA. HMLE and MCF-10A cells treated with either random siRNA or Mule siRNA were incubated with CHX $\left(200 \mu \mathrm{g} \mathrm{ml}^{-1}\right)$ and apoptotic index was analysed by TUNEL assay. We found that inhibition of Mule levels in these cells by siRNA treatment significantly decreased their apoptotic index (HMLE: $61 \pm 5 \%$; MCF-10A: $66 \pm 3 \%$ ) (Figure 4D).

\section{CHX regulation of Mcl-1-binding proteins Puma and HRF}

Puma and HRF (translationally controlled tumour protein) are known to interact with Mcl-1 and increase the stability of Mcl-1. Accordingly, we initially examined the stability of Mcl-1 associating proteins in CHX-treated mammary epithelial and breast cancer cells. Puma (Figure 5A) and HRF (Figure 5C) levels declined with CHX treatment in MCF-10A cells. In most of the CHX-treated breast cancer cell lines, we found increased stability of Mcl-1 associating proteins Puma (Figure 5A, left panel) and HRF (Figure 5C). We further examined the association of Puma, and HRF with Mcl-1 by immunoprecipitating each of these proteins and western blotting for Mcl-1. Since Puma levels declined in CHX-treated MCF-10A cells, we further examined the effects of CHX on Puma-Mcl-1 complexes by immunoprecipitating total cytosolic Puma and immunoblotting for Mcl-1. We found Puma associated with Mcl-1 in control MCF-10A cells but the complex was reduced in CHX-treated cells (Figure 5A, right panel). In both control and CHX-treated MDA-MB-468 cells, Puma-Mcl-1 complex remained stable (Figure $5 \mathrm{~A}$, right panel). To examine whether a decline in Puma could promote Mcl-1 ubiquitination and degradation, we downregulated Puma in breast cancer cell lines with Puma siRNA and examined Mcl-1-Mule complex. Puma levels reduced by $70 \%$ in MDA-MB-468 cells treated with Puma siRNA compared to those treated with scrambled controls (Figure 5B, left panel). A decline in Puma levels did not increase Mcl-1 - Mule complex (data not shown) or ubiquitination of Mcl-1 as assessed by immunoprecipitation and western analysis in breast 
A

$\mathrm{CHX}-\frac{6 \mathrm{~h}}{++} \frac{12 \mathrm{~h}}{++++\frac{16 \mathrm{~h}}{+}} \frac{24 \mathrm{~h}}{++}$

MG132 $\left(20 \mu \mathrm{g} \mathrm{ml}^{-1}\right)-{ }_{-}+{ }_{-}+-+$
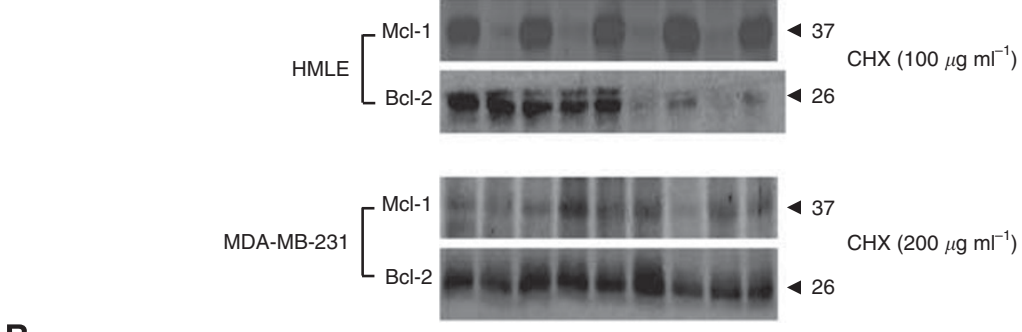

B
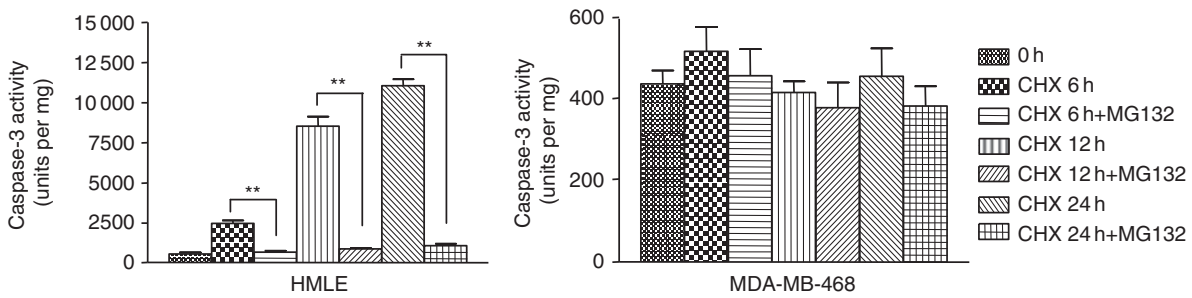

C

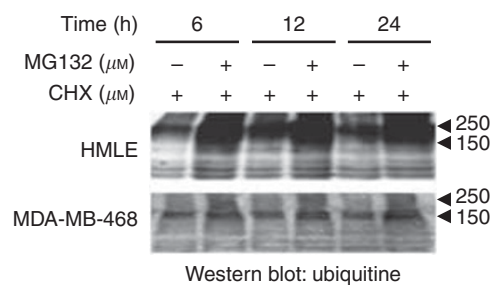

Figure 3 Proteosome-mediated degradation of $\mathrm{Mcl}-\mathrm{I}$ and $\mathrm{BCl}-2$ in HMLE cells can be attenuated by proteosome inhibitor MG I 32. (A) CHX-treated cells were treated with or without MGI 32 and subjected to western blot analysis using anti-Mcl-I and anti-Bcl-2 antibodies. (B) CHX-treated cells were treated with or without MGI 32 and subjected to fluorometric assay for caspase-3 activity. Data represent mean \pm s.e.m. of three independent experiments done in quadruplicates (the asterisks denote statistical significant values compared with $\mathrm{CHX}+\mathrm{MGI} 32$ treatment groups, $* *$ * $\leqslant 0.0 \mathrm{I}$. (C) $\mathrm{CHX}$-treated cells were treated with or without MGI32 and subjected to western blot analysis using anti-Ub antibody.

cancer cells (Figure 5B, right panel). While the levels of HRF declined with $\mathrm{CHX}$ treatment in MCF-10A, its level did not change in MDA-MB-231 cells. However, MDA-MB-468 cells behaved similar to normal mammary cells in response to $\mathrm{CHX}$ (Figure 5C, left panel). We also downregulated Mcl-1-associated HRF in breast cancer cell lines MDA-MB-231 with HRF siRNA (Figure 5C, middle panel) and found a moderate increase in ubiquitination of Mcl-1 levels (Figure 5C, right panel).

\section{Downregulation of pERK1/2 increased Mcl-1-Mule complex in breast cancer cells}

It has been shown that ERK1/2 can phosphorylate and stabilise Mcl-1 in breast cancer cells (Ding et al, 2008). We found ERK1/2 and its active form pERK1/2 upregulated in all the breast cancer cells examined and their levels remain unchanged with $\mathrm{CHX}$ treatment, indicating increased stability of these proteins (Figure 6A). Inactivation of pERK1/2 with MEK inhibitor U0 126 (data not shown) or nitric oxide donor DETA-NONOate promoted the decline of Mcl-1 levels in breast cancer cell line MDA-MB-468 (Figure 6A). Downregulation of pERK1/2 by treatment with MEK inhibitor or nitric oxide donor also increased Mule-Mcl-1 (Figure 6B, left panel) complex and caspase-3 activity in breast cancer cells, indicating induction of apoptosis (Figure 6C, right panel). However, MEK1/2 inhibitor or nitric oxide induced delay and lower caspase- 3 activity in cells compared with higher caspase- 3 activation when Mcl-1 was downregulated by Mcl-1 siRNA (Figure 6C, right panel). These results indicate that HRF and ERK1/2 partially increased the stability of Mcl-1 in breast cancer cells. It is possible that additional mechanisms operate in breast cancer cells that increase stability of Mcl-1 and resistance to apoptosis.

\section{DISCUSSION}

In this study, we found that increased stability of anti-apoptotic proteins like Mcl-1 and Bcl-2 rendered breast cancer cells resistant to $\mathrm{CHX}$-induced apoptosis. However, in mammary epithelial (MCF-10A, HMLE) cells, CHX treatment increased degradation of Mcl-1 through the ubiquitin-dependent proteosomal pathway to induce apoptosis. We show that downregulation of Mcl-1 by Mcl-1 siRNA or inhibiting ERK1/2 through U0126 or nitric oxide treatment increased the sensitivity of breast cancer cells to CHXinduced apoptosis. Our result is consistent with a number of studies which show that drugs like flavopiridol, lipoxygenase inhibitors and roscovitine downregulated both Mcl-1 and Bcl-2 in breast cancer cells, while okadaic acid and immunotoxins among others specifically downregulated only Mcl-1 to induce apoptosis (Rieber et al, 2002; Tong et al, 2002; Wittmann et al, 2003; Andersson et al, 2004; Ortiz-Ferrón et al, 2008).

We found reduced ubiquitination of $\mathrm{Mcl}-1$ and unstable association of Mcl-1 with its specific E3 ligase Mule in breast cancer cells treated with CHX. To our knowledge, this is the first report that has found transient association between Mule and Mcl-1 in breast cancer cells. Mule is a novel ubiquitin that contains domain homologous to E6-AP carboxyl terminus (HECT) as well as Bcl-2 homology region (BH3) domain that allows Mule to specifically interact with Mcl-1 (Warr et al, 2005; Zhong et al, 2005). We were 
A

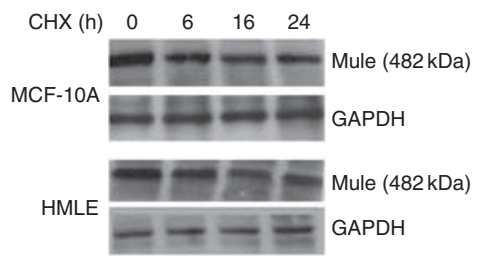

B

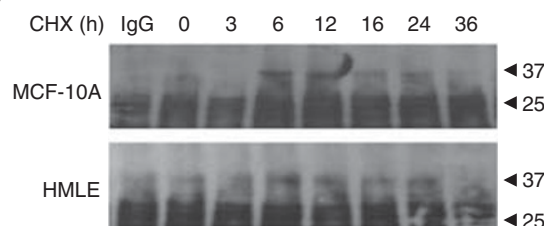

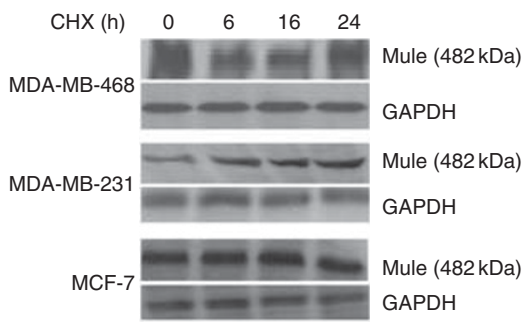

$\begin{array}{llllllll}\mathrm{CHX}(\mathrm{h}) \lg \mathrm{G} & 0 & 3 & 6 & 12 & 16 & 24 & 36\end{array}$

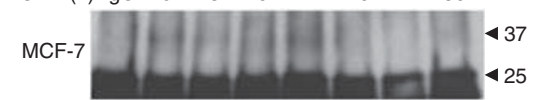

MDA-MB-468

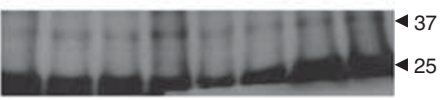

IP: Mule

Blot: Mcl-1

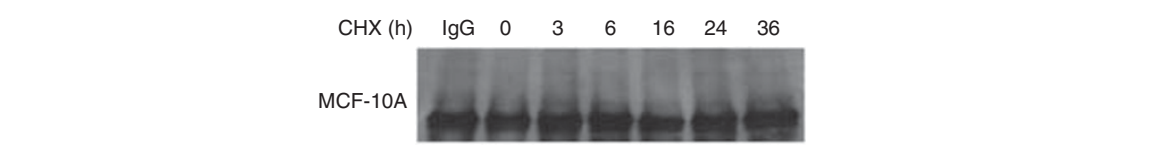

IP: Mule

C

Blot: Bcl-2
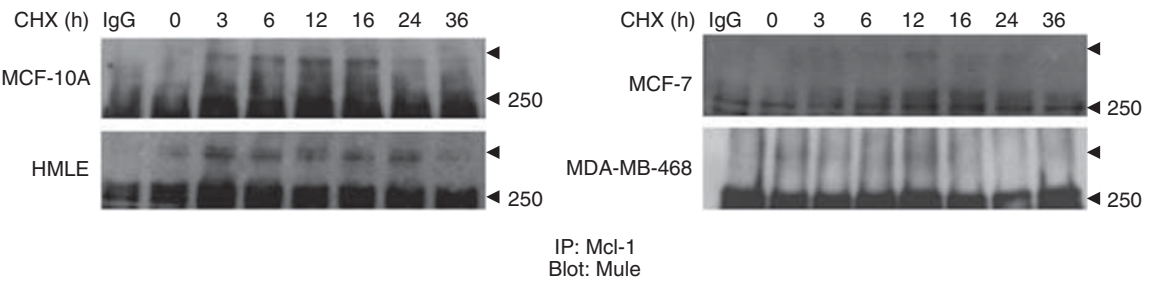

D
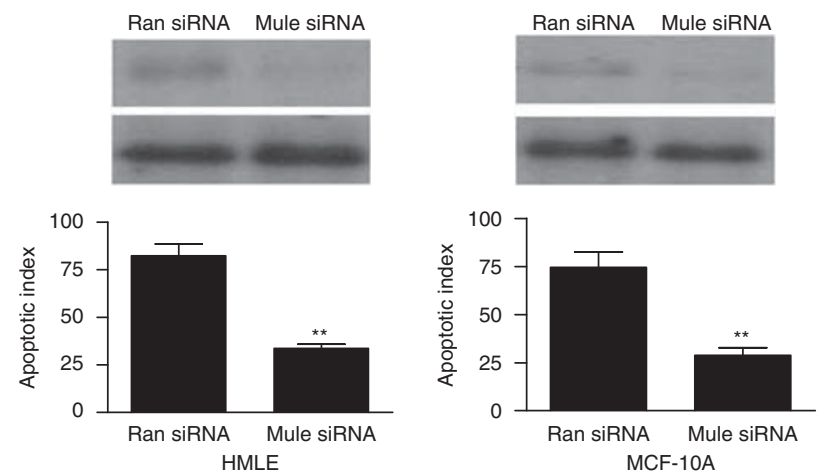

Figure 4 Reduced Mule/Mcl-I complex detected in breast cancer cells compared with mammary epithelial cells. (A) Mammary epithelial cells (MCF- IOA and HMLE, left panel) and breast cancer cells (MDA-MB-468, MDA-MB-23I and MCF-7) were treated with CHX $\left(200 \mu \mathrm{g} \mathrm{ml} \mathrm{I}^{-1}\right)$ for various time points $(0-24 \mathrm{~h})$ and $100 \mu \mathrm{g}$ of protein lysates were immunoblotted using anti-Mule antibody. (B) (Top panel) Mammary epithelial cells (MCF-IOA and HMLE, left panel) and breast cancer cells (MCF-7 and MDA-MB-468, right panel) were treated with CHX $\left(200 \mu \mathrm{g} \mathrm{ml} \mathrm{l}^{-1}\right)$ for various time points $(0-36 \mathrm{~h})$ and immunoprecipitated with anti-Mule antibody or with $\mathrm{lgG}(\mathrm{I} 6 \mathrm{~h})$ and immunoblotted for $\mathrm{Mcl}-\mathrm{I}$. (Bottom panel) MCF-IOA cells were treated with CHX $\left(200 \mu \mathrm{g} \mathrm{ml}^{-1}\right)$ for $0-36 \mathrm{~h}$ and immunoprecipitated with anti-Mule antibody or with $\mathrm{lgG}(\mathrm{I} 6 \mathrm{~h})$ and immunoblotted for Bcl-2. (C) Mammary epithelial cells (MCF-IOA and HMLE, left panel) and breast cancer cells (MCF-7 and MDA-MB-468) were treated with CHX (200 $\left.\mu \mathrm{g} \mathrm{ml}^{-1}\right)$ for various time points $(0-36 \mathrm{~h})$ and immunoprecipitated with anti-Mcl-I antibody or with $\lg \mathrm{G}(\mathrm{I} 6 \mathrm{~h})$ and immunoblotted for Mule. (D) (Top panel) Small-inhibitory RNA (siRNA)mediated inhibition of Mule in mammary epithelial cells (HMLE and MCF-IOA). Western blot analysis showing Mule (top) and GAPDH (bottom). (Bottom panel) Measurement of apoptotic index in random (Ran) and Mule siRNA (Mule siRNA) treated mammary epithelial cells by TUNEL assay after CHX treatment. $* * * 0.01$.

able to detect a stable prolonged association between Mcl-1-Mule in CHX-treated MCF-10A cells, where Mcl-1 undergoes prominent ubiquitination and degradation.

Mcl-1 is stabilised by HRF, which serves as Mcl-1 chaperone and prevents its proteasomal degradation (Liu et al, 2005). Mcl-1 associating protein Puma (p53 upregulated modulator of apoptosis) also increases Mcl-1 stability, but does not ultimately prevent Mcl-1 degradation since its PEST (praline, glutamic acid, serine and threonine) region is still exposed (Mei et al, 2005). Mcl1 also interacts with tankyrase-1, which promotes telomere elongation in human cells, and its overexpression inhibits the activity of Mcl-1L and Mcl-1S (Bae et al, 2003). In our study, downregulation of Puma did not decrease Mcl-1 levels or increase CHX-mediated apoptosis in breast cancer cells. We did find 

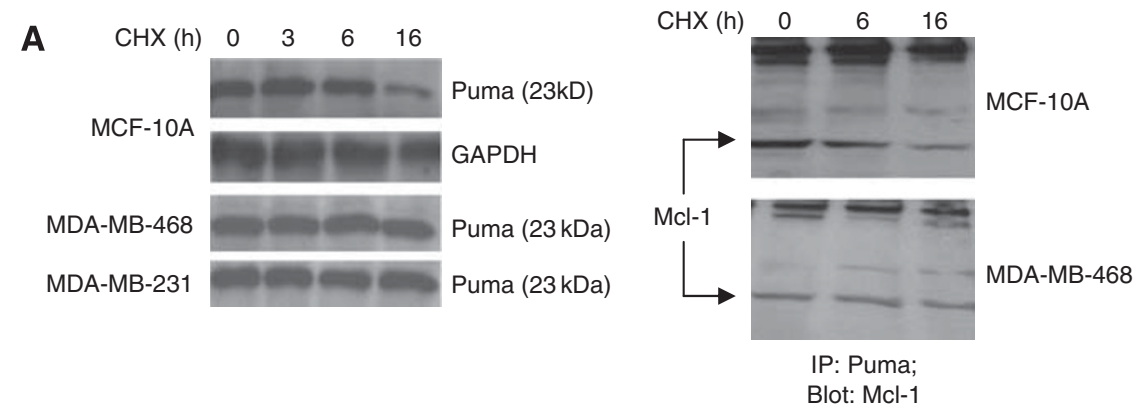

B
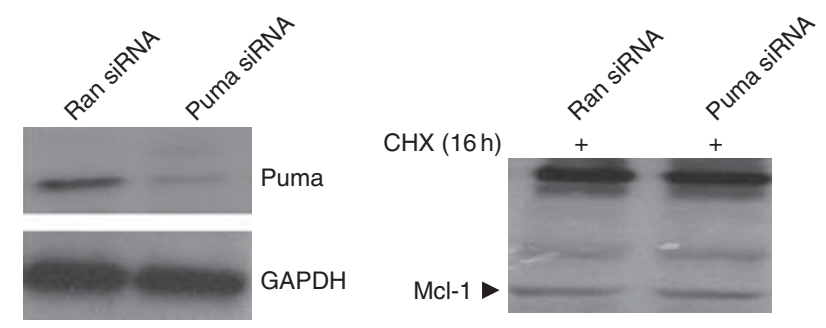

IP: Ub,

MDA-MB-468

Blot: Mcl-1
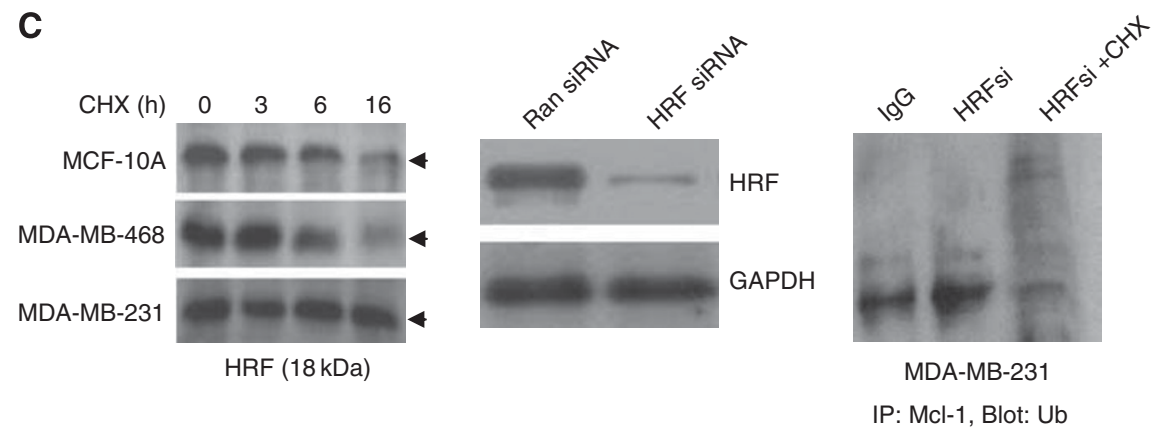

Figure 5 Downregulation of HRF increased Mcl-I ubiquitination. (A) (Left panel) Cells treated with $\mathrm{CHX}\left(200 \mu \mathrm{g} \mathrm{ml}^{-1}\right)$ for various time points $(0-\mid 6 \mathrm{~h}$ ) and $100 \mu \mathrm{g}$ of cell lysates were subjected to immunoblot analysis using anti-Puma antibody. (Right panel) Cells treated with $\mathrm{CHX}$ for various time points $(0-16 \mathrm{~h}$ ) were immunoprecipitated for Puma and immunoblotted with anti- Mcl-I antibody. (B) MDA-MB-468 cells treated with scrambled (Ran siRNA) or HRF siRNA was immunoblotted for Puma and GAPDH (left panel), or immunoprecipitated with ubiquitin (Ub) antibody and blotted for Mcl-I (right panel). (C) (Left panel) Cells treated with $\mathrm{CHX}\left(200 \mu \mathrm{g} \mathrm{ml}^{-1}\right)$ for various time points $(0-16 \mathrm{~h})$ and $100 \mu \mathrm{g}$ of cell lysates were subjected to immunoblot analysis using anti-HRF antibody. (Middle panel) MDA-MB-23I cells treated with scrambled (Ran siRNA) or HRF siRNA and immunoblotted using anti-HRF antibody. (Right panel) Cells treated with HRF siRNA (HR si) or with HRFsi $+\mathrm{CHX}\left(200 \mu \mathrm{g} \mathrm{ml}{ }^{-1}\right)$ were immunoprecipitated with Mcl-I antibody and immunoblotted using anti-Ub antibody.

downregulating HRF in breast cancer cells increased Mcl-1 ubiquitination and apoptosis; however, higher apoptosis induction was observed when Mcl-1 was directly downregulated by Mcl-1 siRNA or indirectly by downregulating pERK1/2. This suggests that mechanisms other than Mcl-1 associating proteins could be operating in breast cancer cells leading to increased stability of Mcl-1.

Although we found that reduced $26 \mathrm{~S}$ proteosomal degradation of key anti-apoptotic proteins increases survival of breast cancer cells, highly selective potent inhibitors of this machinery is emerging as promising new anti-tumour agents (Cardoso et al, 2004; Sterz et al, 2008). The rational that promoted this therapeutic approach was that increased stabilisation of Rpn4, a transcription activator of proteasome genes, severely reduced cell viability under stressed conditions. Rpn4, in addition to being a major mediator of core Rpn4-proteosome feedback circuit also appears to be a major mediator in a stress response network (Xie, 2010). Bortezomib, a proteasome inhibitor, has been shown to have some beneficial effect of in reducing proliferation and metastatic potential of aggressive breast cancer cell lines in in vitro and in vivo model (Jones et al, 2010). However, this compound, which is also the only FDA-approved proteasome inhibitor in clinical use, has shown limited clinical activity against metastatic breast cancer in patients (Yang et al, 2006). Bortezomib, however, has proven effective against some haematologic malignancies like lymphoma where it decreases proliferation, induces apoptosis and enhances sensitivity to various chemotherapy and radiation treatments (Ludwig et al, 2005; Cavo, 2007). Lack of effectiveness of proteosome inhibitors against breast cancer warranted using it in combination with standard cytotoxic agents including docetaxel. A clinical trial using Bortezomib and docetaxel combination as treatment regimen against malignant breast cancer in patients has shown very limited clinical efficacy (Awada et al, 2008). Our current findings may suggest that increasing $26 \mathrm{~S}$ proteosome-mediated degradation of Mcl-1 might have therapeutic benefits in inducing apoptosis in breast cancer cells (Figure 6D).

Since we found transient association between Mcl-1 and Mule in cancer cells, in addition to HRF and pERK1/2 we are examining deubiquitinating enzymes (DUBs) that function downstream in ubiquitin pathways and have the potential to be the final editors of protein ubiquitination status and thus determine substrate fate (Millard and Wood, 2006). In several studies, DUBs have been implicated in regulating the stability of several proteins and can 
$\begin{array}{lllllll}\text { A } & \text { (h) } & 0 & 4 & 8 & 16 & 24\end{array}$

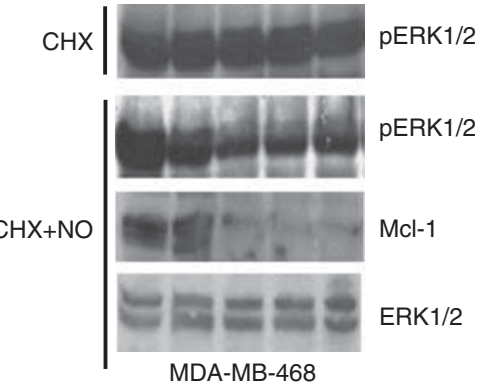

B

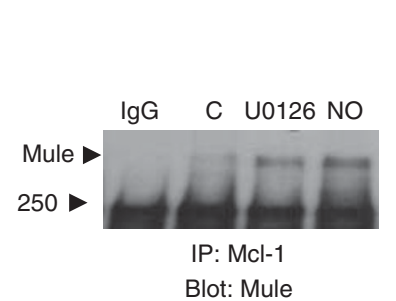

MDA-MB-468

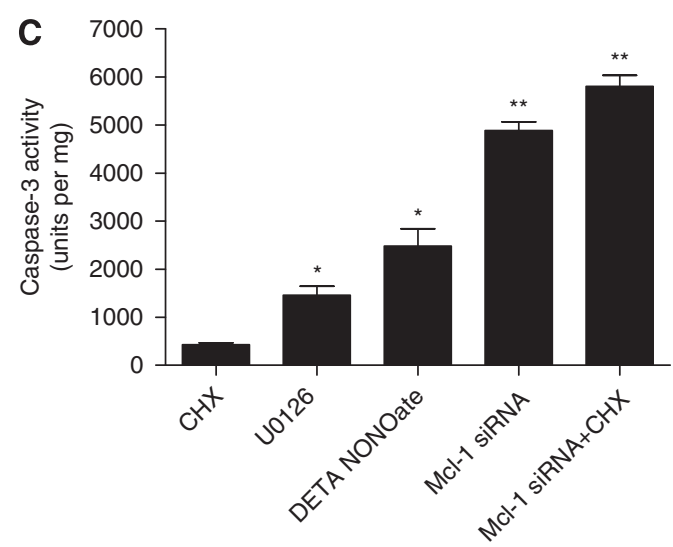

D

Mammary epithelial cells

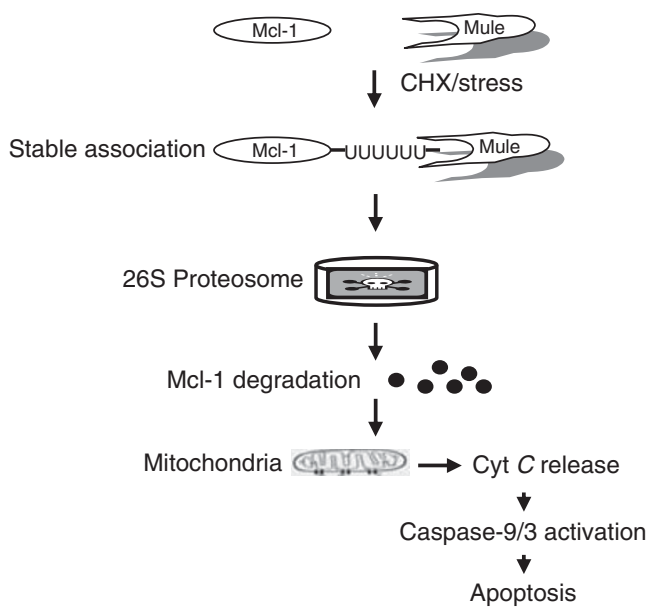

Breast cancer cells

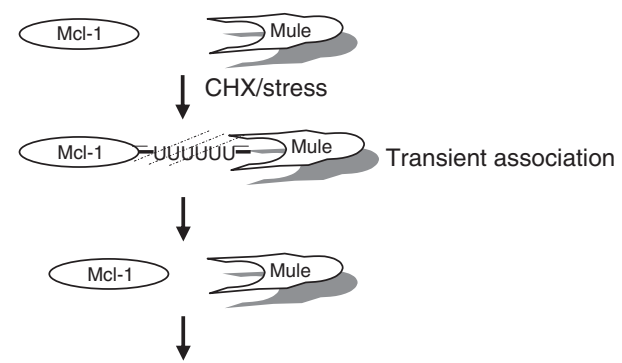

No Mcl-1 degradation

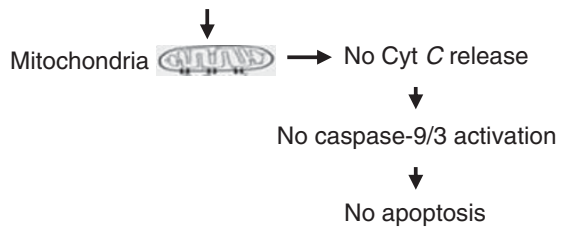

Figure 6 Downregulation of ERKI/2 increases apoptosis in breast cancer cells. (A) MDA-MB-468 cells were treated with either CHX, alone or in combination with DETA-NONOate, a nitric oxide (NO) donor for $24 \mathrm{~h}$ and immunoblotted using anti-pERKI/2, ERKI/2 or Mcl-I antibodies. (B) Cells treated with U0 I26 (I0 $\left.\mathrm{g} \mathrm{ml}^{-1}\right)$, DETA-NONOate, I mM) or IgG for $48 \mathrm{~h}$ were lysed, immunoprecipitated with Mcl-I antibody and blotted for Mule. (C) MDA-MB-468 cells were subjected to various treatments and $30 \mu \mathrm{g}$ of total protein lysates were analysed for caspase-3 enzymatic activity. (D) Flow diagram explaining sensitivity of mammary epithelial cells or resistance of cancer cells to CHX treatment.

extend the half-life of proteins destined for proteasomal degradation by catalysing hydrolysis of isopeptide bond in ubiquitin protein conjugates (Graner et al, 2004; Sheng et al, 2006; Pereg et al, 2010). Some of these DUBs are overexpressed in breast cancer (McFarlane et al, 2010).

Few studies have correlated increased stability of proteins with oncogenicity or tumour progression. Signalling cascades in cancer cells that increase resistance to apoptosis has been targeted to control tumourigenesis. Our finding of increased stability of Mcl-1 in breast cancer cells due to reduction of Mcl-1-Mule complex introduces new players that can be targeted for therapeutic interventions to induce apoptosis in breast cancer. Further studies focusing on better understanding of deubiquitination-ubiquitin cycle's role are needed to develop new therapeutic targets for breast cancer therapy.

\section{ACKNOWLEDGEMENTS}

This work was supported by National Institute of Health Grants 1R03 HD053888 (SP), SC1AG033407 (RS), Palomba Weingarten, Allegra Charach Cancer Research Fund (GC), and in part by Charles Drew University MSI endowment sub-award (5S21MD000103, RS) and 5U54CA 143931. 


\section{REFERENCES}

Abdelmohsen K, Lal A, Kim HH, Gorospe M (2007) Posttranscriptional orchestration of an anti-apoptotic program by HuR. Cell Cycle 6: 1288-1292

Andersson Y, Juell S, Fodstad $\varnothing$ (2004) Down regulation of the antiapoptotic MCL-1 protein and apoptosis in MA-11 breast cancer cells induced by an anti-epidermal growth factor receptor-Pseudomonas exotoxin a immunotoxin. Int J Cancer 112: $475-483$

Awada A, Albanell J, Canney PA, Dirix LY, Gil T, Cardoso F, Gascon P, Piccart MJ, Baselga J (2008) Bortezomib/docetaxel combination therapy in patients with anthracycline-pretreated advanced/metastatic breast cancer: a phase I/II dose-escalation study. Br J Cancer 98: 1500-1507

Bae J, Donigian JR, Hsueh AJ (2003) Tankyrase 1 interacts with Mcl-1 proteins and inhibits their regulation of apoptosis. J Biol Chem 278: $5195-5204$

Callagy GM, Webber MJ, Pharoah PD, Caldas C (2008) Meta-analysis confirms BCL2 is an independent prognostic marker in breast cancer. BMC Cancer 8: 153

Cardoso F, Ross JS, Picart MJ, Sotiriou C, Durbecq V (2004) Targeting the ubiquitin-proteasome pathway in breast cancer. Clin Breast Cancer 5: $148-157$

Cavo M (2007) Current status of bortezomib in the treatment of multiple myeloma. Curr Hematol Malig Rep 2: $128-137$

Chen D, Kon N, Li M, Zhang W, Qin J, Gu W (2005) ARF-BP1/Mule is a critical mediator of the ARF tumor suppressor. Cell 121: $1071-1083$

Ding Q, Huo L, Yang JY, Xia W, Wei Y, Liao Y, Chang CJ, Yang Y, Lai CC, Lee DF, Yen CJ, Chen YJ, Hsu JM, Kuo HP, Lin CY, Tsai FJ, Li LY, Tsai $\mathrm{CH}$, Hung MC (2008) Down-regulation of myeloid cell leukemia-1 through inhibiting Erk/Pin 1 pathway by sorafenib facilitates chemosensitization in breast cancer. Cancer Res 68: 6109-6117

Djeu JY, Wei S (2009) Clusterin and chemoresistance. Adv Cancer Res 105: $77-92$

Graner E, Tang D, Rossi S, Baron A, Migita T, Weinstein LJ, Lechpammer M, Huesken D, Zimmermann J, Signoretti S, Loda M (2004) The isopeptidase USP2a regulates the stability of fatty acid synthase in prostate cancer. Cancer Cell 5: 253-261

Jetzt AE, Cheng JS, Tumer NE, Cohick WS (2009) Ricin A-chain requires cJun N-terminal kinase to induce apoptosis in nontransformed epithelial cells. Int J Biochem Cell Biol 41: 2503-2510

Jones MD, Liu JC, Barthel TK, Hussain S, Lovria E, Cheng D, Schoonmaker JA, Mulay S, Ayers DC, Bouxsein ML, Stein GS, Mukherjee S, Lian JB (2010) A proteasome inhibitor, bortezomib, inhibits breast cancer growth and reduces osteolysis by downregulating metastatic genes. Clin Cancer Res 16: $4978-4989$

Kutuk O, Letai A (2008) Alteration of the mitochondrial apoptotic pathway is key to acquired paclitaxel resistance and can be reversed by ABT-737. Cancer Res 68: 7985-7994

Li M, Wang Y, Hung MC, Kannan P (2006) Inefficient proteasomaldegradation pathway stabilizes AP-2alpha and activates HER-2/neu gene in breast cancer. Int $J$ Cancer 118: 802-811

Liu H, Peng HW, Cheng YS, Yuan HS, Yang-Yen HF (2005) Stabilization and enhancement of the antiapoptotic activity of Mcl-1 by TCTP. Mol Cell Biol 25: 3117-3126

Ludwig H, Khayat D, Giaccone G, Facon T (2005) Proteasome inhibition and its clinical prospects in the treatment of hematologic and solid malignancies. Cancer 104: $1794-1807$

McBride WH, Iwamoto KS, Syljuasen R, Pervan M, Pajonk F (2003) The role of the ubiquitin/proteasome system in cellular responses to radiation. Oncogene 22: $5755-5773$

McCubrey JA, Steelman LS, Chappell WH, Abrams SL, Wong EW, Chang F, Lehmann B, Terrian DM, Milella M, Tafuri A, Stivala F, Libra M, Basecke J, Evangelisti C, Martelli AM, Franklin RA (2007) Roles of the Raf/MEK/ERK pathway in cell growth, malignant transformation and drug resistance. Biochim Biophys Acta 1773: 1263 - 1284

McFarlane C, Kelvin AA, de la Vega M, Govender U, Scott CJ, Burrows JF, Johnston JA (2010) The deubiquitinating enzyme USP17 is highly expressed in tumor biopsies, is cell cycle regulated, and is required for G1-S progression. Cancer Res 70: 3329-3339

Mei Y, Du W, Yang Y, Wu M (2005) Puma(*)Mcl-1 interaction is not sufficient to prevent rapid degradation of Mcl-1. Oncogene 24: $7224-7237$

Millard SM, Wood SA (2006) Riding the DUBway: regulation of protein trafficking by deubiquitylating enzymes. J Cell Biol 173: 463-468

Müllauer L, Mosberger I, Grusch M, Rudas M, Chott A (2000) Fas ligand is expressed in normal breast epithelial cells and is frequently up-regulated in breast cancer. J Pathol 190: 20-30
Nuñez G, Hockenbery D, McDonnell TJ, Sorensen CM, Korsmeyer SJ (1991) Bcl-2 maintains B cell memory. Nature 353: 71-73

Ortiz-Ferrón G, Yerbes R, Eramo A, López-Pérez AI, De Maria R, López-Rivas A (2008) Roscovitine sensitizes breast cancer cells to TRAIL-induced apoptosis through a pleiotropic mechanism. Cell Res 18: $664-676$

Parsons JL, Tait PS, Finch D, Dianova II, Edelmann MJ, Khoronenkova SV, Kessler BM, Sharma RA, McKenna WG, Dianov GL (2009) Ubiquitin ligase ARF-BP1/Mule modulates base excision repair. EMBO J 28: 3207 - 3215

Pellikainen JM, Kosma VM (2007) Activator protein-2 in carcinogenesis with a special reference to breast cancer-a mini review. Int J Cancer 120: $2061-2067$

Pereg Y, Liu BY, O’Rourke KM, Sagolla M, Dey A, Komuves L, French DM, Dixit VM (2010) Ubiquitin hydrolase Dub3 promotes oncogenic transformation by stabilizing Cdc25A. Nat Cell Biol 12: 400-406

Pervin S, Singh R, Chaudhuri G (2003) Nitric-oxide-induced Bax integration into the mitochondrial membrane commits MDA-MB-468 cells to apoptosis: essential role of Akt. Cancer Res 63: 5470-5479

Pervin S, Singh R, Hernandez E, Wu G, Chaudhuri G (2007) Nitric oxide in physiologic concentrations targets the translational machinery to increase the proliferation of human breast cancer cells: involvement of mammalian target of rapamycin/eIF4E pathway. Cancer Res 67: 289-299

Petroski MD (2008) The ubiquitin system, disease, and drug discovery. BMC Biochem 9(Suppl 1): S7

Rieber M, Medina JD, Strasberg-Rieber M (2002) Relationship of Mcl-1 isoforms, ratio p21WAF1/cyclin $\mathrm{A}$, and Jun kinase phosphorylation to apoptosis in human breast carcinomas. Biochem Biophys Res Commun 297: $943-949$

Schulte TW, Blagosklonny MV, Ingui C, Neckers L (1995) Disruption of the Raf-1-Hsp90 molecular complex results in destabilization of Raf-1 and loss of Raf-1-Ras association. J Biol Chem 270: 24585-24588

Sheng Y, Saridakis V, Sarkari F, Duan S, Wu T, Arrowsmith CH, Frappier L (2006) Molecular recognition of p53 and MDM2 by USP7/HAUSP. Nat Struct Mol Biol 13: 285-291

Shimazu T, Degenhardt K, Nur-E-Kamal A, Zhang J, Yoshida T, Zhang Y, Mathew R, White E, Inouye M (2007) NBK/BIK antagonizes MCL-1 and $\mathrm{BCL}-\mathrm{XL}$ and activates BAK-mediated apoptosis in response to protein synthesis inhibition. Genes Dev 21: 929-941

Singh R, Pervin S, Karimi A, Cederbaum S, Chaudhuri G (2000) Arginase activity in human breast cancer cell lines: $N$ (omega)-hydroxy-L-arginine selectively inhibits cell proliferation and induces apoptosis in MDA-MB468 cells. Cancer Res 60: 3305-3312

Sterz J, von Metzler I, Hahne JC, Lamottke B, Rademacher J, Heider U, Terpos E, Sezer O (2008) The potential of proteasome inhibitors in cancer therapy. Expert Opin Investig Drugs 17: 879-895

Sun Y (2006) E3 ubiquitin ligases as cancer targets and biomarkers. Neoplasia 8: $645-654$

Thompson SJ, Loftus LT, Ashley MD, Meller R (2008) Ubiquitinproteasome system as a modulator of cell fate. Curr Opin Pharmacol 8: $90-95$

Tong WG, Ding XZ, Adrian TE (2002) The mechanisms of lipoxygenase inhibitor-induced apoptosis in human breast cancer cells. Biochem Biophys Res Commun 296: $942-948$

Wang P, Valentijn AJ, Gilmore AP, Streuli CH (2003) Early events in the anoikis program occur in the absence of caspase activation. J Biol Chem 278: $19917-19925$

Warr MR, Acoca S, Liu Z, Germain M, Watson M, Blanchette M, Wing SS, Shore GC (2005) BH3-ligand regulates access of MCL-1 to its E3 ligase. FEBS Lett 579: 5603-5608

Wittmann S, Bali P, Donapaty S, Nimmanapalli R, Guo F, Yamaguchi H, Huang M, Jove R, Wang HG, Bhalla K (2003) Flavopiridol downregulates anti-apoptotic proteins and sensitizes human breast cancer cells to epothilone B-induced apoptosis. Cancer Res 63: 93 -99

Xie Y (2010) Feedback regulation of proteasome gene expression and its implications in cancer therapy. Cancer Metastasis Rev 29: 687-693

Yang CH, Gonzalez-Angulo AM, Reuben JM, Booser DJ, Pusztai L, Krishnamurthy S, Esseltine D, Stec J, Broglio KR, Islam R, Hortobagyi GN, Cristofanilli M (2006) Bortezomib (VELCADE) in metastatic breast cancer: pharmacodynamics, biological effects, and prediction of clinical benefits. Ann Oncol 17: 813-817

Zhong Q, Gao W, Du F, Wang X (2005) Mule/ARF-BP1, a BH3-only E3 ubiquitin ligase, catalyzes the polyubiquitination of $\mathrm{Mcl}-1$ and regulates apoptosis. Cell 121: $1085-1095$ 